\title{
Las primeras décadas del radioteatro argentino: disputas en la construcción de la identidad actoral
}

\author{
Valeria Andrea Misevich \\ Universidad de Buenos Aires, Argentina \\ vamisevich@hotmail.com
}

Fecha de recepción: 29/03/2020. Fecha de aceptación: 30/04/2020.

\begin{abstract}
Resumen
El radioteatro fue el fenómeno que revolucionó el campo cultural en los años 30 en Argentina. Confluyeron en él artistas de toda índole, ampliando el mercado laboral en un contexto de crisis económica y alta conflictividad social. Ahora bien, durante la década del 30 y parte del 40, el radioteatro cosechó un sinnúmero de críticas que visibilizaron las concepciones arraigadas en la sociedad sobre el arte, la cultura, el rol de los medios y los artistas. Nos preguntamos, entonces, ¿qué sucedía con la legitimidad y la profesionalización de estos artistas en un período de explosión de industrias culturales? ¿Cómo se posicionaron los sindicatos que los representaban frente al fenómeno radioteatral? Apelando a conceptos teóricos desarrollados por Mauro (2014a, 2014b, 2018a, 2018b), Pellettieri (2002) y Bourdieu $(1967,2000$ ) y analizando los discursos que circularon en el campo cultural argentino del momento, este trabajo se propone dar cuenta no sólo de los prejuicios y las dificultades que afrontaron lxs profesionales de la actuación en un momento crucial de su propia historia como colectivo, sino también la proyección que ciertas concepciones aún poseen, atentando contra la autopercepción de lxs mismxs en tanto trabajadorxs de la cultura.
\end{abstract}

Palabras clave: Radioteatro, industrias culturales, campo intelectual, actuación, sindicato

The First Decades of Argentinian Radiodrama: Disputes in the Construction of an Acting Identity

\begin{abstract}
Radio drama was a phenomenon which revolutionised the cultural field in Argentina's 1930s. Artists of all sorts converged, expanding the labour field in a context of economic crisis and social unrest. However, during the 1930 s and part of the 1940 , radio drama was roundly criticised, thus showing society's deeply rooted conceptions regarding art, culture, the role of the media and artists. We ask ourselves, then, what happened with the legitimacy and the professionalization of artists in a period
\end{abstract}


of cultural explosion? How did their unions face the radio drama phenomenon? Following theoretical concepts developed by Mauro (2014a, 2014b, 2018a, 2018b), Pellettieri (2002) and Bourdieu $(1967,2000)$ and analising the discourses that circulated through Argentina's cultural field of the time, this paper aims to shed light not only on the prejudice and obstacles faced by acting professionals at a turning point in their history as a collective, but also on the projection that some conceptions still have, acting against cultural workers' self-perception.

Keywords: Radio Drama - Cultural Industries- Intellectual Field - Acting - Labor Union

\section{Introducción}

El radioteatro fue el fenómeno que revolucionó el campo cultural en los años 30 en Argentina. Confluyeron en él artistas de toda índole, con y sin experiencia, ampliando el mercado laboral en un contexto de crisis económica y alta conflictividad social.

El impacto de la crisis internacional de 1929 se sintió especialmente en la caída de las exportaciones tradicionales de carne y cereales y en las consecuentes dificultades para la obtención de capitales y divisas necesarias para el pago de las importaciones. La desocupación apareció también como la más evidente de las consecuencias de dicha crisis, en un contexto de creciente inestabilidad política. Según González Leandri "un estudio gubernamental del año 1932 confirmó la existencia de 90.000 desocupados en Buenos Aires y de 334.000 en todo el país, contra 15.000 que había a comienzos de 1930" (2001:211-2).

La crisis afectó profundamente al campo teatral: se disolvieron compañías, se interrumpieron temporadas y bajaron los salarios, y si bien el teatro durante las primeras dos décadas del siglo XX se había constituido como la forma masiva de entretenimiento por antonomasia, la década del 30 verá consolidarse al cine y fundamentalmente a la radio, como medios masivos de entretenimiento. Las transformaciones sociales de los sectores medios

(...) no sólo repercutieron en su forma de vida y de socialización, sino también en sus modos de esparcimiento, lo cual influenció directamente en sus gustos, preferencias y prácticas de consumo cultural (...). Como corolario, se produjo un paulatino declive del teatro como forma popular de entretenimiento, pasando a competir, ahora sí desventajadamente, con el cine, la radio y el espectáculo deportivo. (...) Caudarella (2016) afirma que entre 1925 y 1927 la audiencia teatral se redujo un $16 \%$ y la recaudación, un 42,82\%, Klein (1988) sostiene que el número de espectadores descendió de siete millones registrados en 1928, a aproximadamente la mitad para 1933. (Mauro, 2018b:211)

Los orígenes del fenómeno radiofónico en nuestro país se remontan a 1920, y el debate central sobre el rol del nuevo medio se había instalado y seguía vigente: educación o entretenimiento. $\mathrm{Y}$, específicamente, en el caso de proponerse entretener, ¿con qué tipo de audiciones debía hacerlo? ¿Conciertos, óperas, tango, radioteatros? Lo culto y lo popular como opciones contrapuestas parecían no admitir contaminaciones y se planteaban al mismo tiempo, dudas sobre las posibilidades de la radio de producir bienes culturales, y no circunscribirse a la mera reproducción de obras legitimadas. El trabajo de López Barros, analizando films de la década del 30 donde la radio cumple un rol importante, nos permite acceder a un imaginario de época. En el caso de Ídolos de la radio (E. Morera, 1934) o RadioBar (M. Romero, 1936), según la autora, lo que se instala fundamentalmente 
es la polémica entre el "arte" (entendido como manifestaciones artísticas de la denominada alta cultura, ligadas en el caso de la radio a la música lírica) versus la cultura popular (en la que se inscribe el tango). Una situación de este tipo es recreada por la actriz Olinda Bozán en "RadioBar" en la que, luego del fracaso artístico, aparece la queja sobre la falta de educación del pueblo que sólo quiere tango. (...) "El arte y la radio no pueden estar unidas" (se lamenta el personaje de Olinda Bozán) (López Barros, 2013:110).

En este marco, hace explosión el radioteatro en nuestro país. Para comprender la magnitud del fenómeno radial bastan algunos datos: según Elíades (2003) en 1922 se contabilizaron mil aparatos receptores en nuestro país, mientras que en 1936 ya se habla de 1.500.000. En 1940 funcionaban más de cincuenta estaciones radiales en todo el país.

El primer radioteatro, Chispazos de Tradición, hace su debut en 1932 en Radio Belgrano de Jaime Yankelevich. La creación de Andrés González Pulido

contaba con un elenco de actores que representaban a lo largo de las semanas diferentes argumentos que llegaban a durar hasta un mes. El éxito de este radioteatro fue de tal dimensión que los argumentos de las novelas se publicaban y eran comprados por las escuelas para poder representarlos, además la compañía salía de gira por los barrios y pueblos exponiendo los últimos éxitos de la radionovela. (...) Muchos son los oyentes que recuerdan cómo Chispazos de tradición paralizaba la ciudad (Matallana, 2013:157).

Se trataba de una mezcla de canciones folklóricas, dramas, relatos y recitados que se desarrollaban en un ambiente campero. El género se fue conformando poco a poco hasta instituirse en una serie continuada de episodios melodramáticos. Se fueron diversificando las temáticas, buscando ganar audiencia y llegar a públicos de todo tipo.

Ahora bien, durante la década del 30 y parte del 40, el radioteatro, en pleno éxito, cosechó un sinnúmero de críticas desde distintos sectores que visibilizaron concepciones arraigadas en la sociedad sobre el arte, la cultura y el rol de los artistas. Al mismo tiempo, el nuevo medio y, especialmente el nuevo género, constituyeron una importantísima fuente de trabajo en un mercado laboral en crisis.

Nos preguntamos entonces qué reacción tuvo el campo intelectual y el campo teatral frente al radioteatro. ¿En qué situación se encontraban aquellxs que incursionaron en el radioteatro como actores y actrices?

Cuando hablamos de campo intelectual y campo teatral, lo hacemos desde la perspectiva desarrollada por Pierre Bourdieu (1967) y nos valemos de la reformulación de Osvaldo Pellettieri (2002) en el terreno específico de las artes escénicas. El campo teatral, como espacio social relativamente autónomo del poder político y económico, conformado por diversos agentes (autores, actores, directores, productores, instituciones, etc.) que luchan por apropiarse del capital cultural y obtener un lugar central en el mismo, será el foco de nuestro trabajo. Tanto las relaciones de alianza que se traban buscando imponer como legítimo aquello que los define como grupo; como también aquellas estrategias que tienen la intención de expulsar o excluir aquello que se considera una perturbación, constituyen una dinámica compleja que intentaremos desentrañar.

La categoría de "Yo Actor" propuesta por Karina Mauro (2014b) será de gran utilidad ya que condensa conceptualmente la problemática histórica de la comunidad actoral. 
Según la autora, esta identidad narrativa compartida se encuentra conformada por un relato que permite a actores y actrices darse una imagen de sí mismos, partiendo de un repertorio de conductas y cualidades específicas. Se halla siempre en proceso de construcción y se ve amenazada por "la histórica ambigüedad de la condición actoral, ubicada en la encrucijada entre una tipificación que señala al actor como artista y otra que lo señala como trabajador" (Mauro, 2014a: 109). Es esta última característica dicotómica la que parece convertirse en un factor determinante a la hora de estudiar las dinámicas del campo teatral e intelectual del período señalado, donde el éxito masivo del radioteatro y la apertura de un espacio laboral nuevo generaron reacciones virulentas por parte de aquellos que ocupaban posiciones centrales. Tanto los representantes de una cultura culta dominante y conservadora como los intelectuales progresistas ya se habían pronunciado contra el teatro popular y de la misma manera se manifestaron contra el radioteatro.

La intención deliberada de exclusión o descalificación fue una constante. Será necesario el transcurrir de una década para que la institución que hegemoniza la representación de actores y actrices argentinas comience a reconocer de manera oficial el valor del radioteatro como medio legítimo donde desarrollarse profesionalmente.

\section{Artistas aficionados y profesionales: críticas y hostilidad del campo intelectual}

Entre 1935 y 1943, según Matallana, el radioteatro experimentó un rápido crecimiento que trajo aparejada la profesionalización del medio y "hacer radio había dejado de ser una mezcla de improvisación y de saberes técnicos para transformarse en una actividad profesional". La profesionalización incluye tanto a los técnicos como a los actores y actrices, "quedando cada vez más acotado el espacio para los aficionados" (Matallana, 2013:159).

Podemos señalar como primera categoría la idea de aficionadxs, hombres, mujeres, niños y niñas que vieron la posibilidad laboral y acudieron a los estudios de radio para probarse: se realizaban concursos y castings abiertos, la mayoría de las veces auspiciados por grandes empresas, tanto para actuar como para cantar.

Citemos como ejemplo el caso de Nelly Láinez, que, con apenas doce años, comenzó su carrera artística acudiendo a la emisora Radio Porteña en 1932 para probarse, siendo contratada para participar de un radioteatro de temática policial y que luego se convertiría en un actriz de renombre.

Por otro lado, el cine se convierte, sin duda, en una fuente fundamental para reconstruir alguna de esas prácticas: Ídolos de la radio (E. Morera, 1934) y RadioBar (M. Romero, 1936) ponen en escena el funcionamiento de las emisoras y sus procedimientos de reclutamiento. En el primer caso, no sólo vemos el concurso de cancionistas donde participará la joven Ada Falcón incentivada por su familia, sino también una parodia del modo de actuación en el radioteatro. En el segundo caso, se pone el acento en el sueño de jóvenes trabajadores de una boîte de convertirse en estrella de radio.

La industria radiofónica se desarrollaba buscando fundamentalmente el rédito económico y el crecimiento de los niveles de audiencia, pero era consciente de la necesidad de contar con un mínimo de legitimidad y reconocimiento por parte del campo intelectual. En esta contienda, el radioteatro no quedaba excluido. Dos de los primeros radioteatros presentan elecciones completamente distintas en su producción: Bajo la Santa Federación (1933), en un claro intento por diferenciarse del gran éxito del precursor Chispazos de Tradición, recurrió a hombres de letras como Héctor 
Pérez Blomberg y Carlos Viale Paz, dramaturgos ambos, para escribir el guion. El radioteatro fue emitido por dos radios, Nacional y Porteña, en diferentes horarios, y contaba con un elenco que no provenía del teatro popular. Chispazos de Tradición había sido escrito por González Pulido, actor y escritor español denostado por la crítica y la clase intelectual. Bajo la Santa Federación decía "poseer mayor mérito literario y precisión histórica"(Karush, 2013:97). Los primeros radioteatros ya eran plenamente conscientes de las estrategias de mercado que debían poner en práctica para ofrecer una variedad de productos tendientes a captar diferentes sectores de la audiencia.

Actores y actrices de muy distinta proveniencia se encontraban en el mismo medio, pero no se concebían aún como parte de un colectivo que trascendiera aquellas diferencias.

Por otra parte, rápidamente la integración vertical se convirtió en una característica fundamental para la consolidación de las industrias culturales, posibilitando el flujo de artistas entre los distintos medios. Tomemos como ejemplo el caso de Jaime Yankelevich:

En esa misma época [1934] el dueño de Radio Belgrano fundó, junto a Francisco Canaro, la Productora de Cinematografía Argentina Río de la Plata. (...) Esta nueva empresa se sumaba a la producción de espectáculos teatrales y, años más tarde, al inicio de una publicación gráfica dedicada al mundo de la radio y el espectáculo en general (la revista Antena). De esta forma, Yankelevich hacía más eficiente la integración vertical de producción en la industria del entretenimiento: promovía la venta y producción de aparatos de radios pero, además, poseía una de las emisoras más importantes de carácter nacional como así también catorce repetidoras en todo el país; era socio de una compañía cinematográfica, de una empresa de producción de espectáculos y de una revista dedicada a la difusión de noticias del espectáculo, y posteriormente [década del 40] incluiría la empresa de publicidad, de tal modo que la producción del espectáculo circulaba a través de sus diversos medios (Matallana, 2013:155).

Si bien el funcionamiento de la radiofonía posicionaba a los actores y actrices del radioteatro en un lugar de enorme popularidad, el éxito logrado resultaba inversamente proporcional al reconocimiento obtenido en la prensa o en los sectores ilustrados. Si bien "las audiencias populares aceptaron mayoritariamente el rol comercial que la radio tenía y su propia identidad como consumidores del mundo de la radiodifusión" (Matallana, 2013:153), el campo intelectual y los propios hacedores del medio se debatían en torno a su función social, mientras que el Estado se involucraba casi exclusivamente en lo que concernía a los contenidos con la intención de garantizar el buen gusto y la moral. Con el decreto de mayo de 1933, se reglamenta el funcionamiento de las estaciones de radio, que deben constituirse en exponentes de la cultura y de la ciencia, acrecentando el nivel intelectual y moral de los oyentes. No interviene en otros aspectos claves de la industria.

Durante la década del 30, la condición de ilegitimidad del medio radiofónico como productor de bienes culturales parecía proyectarse y profundizarse si nos referimos al radioteatro, producto asociado frecuentemente a un auspiciante o una marca comercial. Esto colocaba en una posición periférica del campo intelectual y teatral a quienes optaban por desarrollarse allí y no en el teatro culto o independiente, acentuando el carácter mercantil de su práctica e imposibilitando sustancialmente la afirmación del YoActor. Berman analiza las publicidades de las revistas de la época y sostiene que

Desde el comienzo de la década del '30 estos avisos de programas aparecían enmarcados en avisos publicitarios de productos: Jabón Tocador Palmolive, Lysoform, 
Tónico Bayer, Leche de magnesia Phillips, aceite Ricoltore, en fin, una larguísima lista de productos y, en algún lugar, abajo o a un costado, como pequeñas pastillas, aparecían los avisos de radioteatros" (2010:369).

Siguiendo a Bourdieu (2000), no resulta difícil reconocer los distintos tipos de relaciones que se suscitaban dentro del campo. Unas, propiciaban alianzas, y otras, por el contrario, tendían hacia la exclusión o marginación de ciertos agentes. Dentro de las primeras se establecen intercambios con miembros de posiciones similares, que permiten elaborar coaliciones para obtener apoyo y mutuo reconocimiento en cuanto a quienes son y a aquello que producen. Dentro de la comunidad actoral, estas relaciones pareciera que no se desarrollaron de manera significativa durante el período estudiado, ya que dentro del campo teatral, los actores y actrices del teatro popular, del circo, y específicamente del radioteatro, no eran reconocidos como pares por los sectores cultos.

Es por esto que nos centraremos en las segundas, las estrategias de exclusión, que se multiplicaron al toparse con agentes y productos provenientes de las nuevas industrias culturales y no permitieron a lo largo de la década del 30 ni el reconocimiento de estos actores y actrices por la asociación gremial mayoritaria ni tampoco la organización interna y diferenciada para luchar por el mejoramiento de sus condiciones laborales.

Las críticas hacia el radioteatro no solo provenían de las revistas dedicadas al espectáculo, que aun en 1940 sostenían que el género no lograba alcanzar la dignidad necesaria. Berman y Fraticelli (2008) realizaron un minucioso trabajo de análisis sobre las críticas de radioteatros en las revistas Radiolandia y Antena, concluyendo que son casi inexistentes los elogios, aunque hacen la salvedad sobre algunos comentarios que hablan de la evolución en los elencos. Karush, en coincidencia, sostiene que

la falta de variedad y la innovación en la radio fue un tema frecuente de los editoriales de las revistas de entretenimiento. Una columna típica responsabilizaba por la tendencia a la imitación al único objetivo de hacer dinero que conducía a las emisoras a copiar cualquier programa popular, opinión compartida por el funcionario de la comisión nombrado por el presidente Ortiz (Karush, 2013:98).

Los medios de los sectores cultos dominantes y de aquellos ultraconservadores de la sociedad argentina también se expresaron negativamente. Betina González analiza la presencia de la radio en la revista Sur, e indica que "el radioteatro, [fue el] blanco favorito de los intelectuales de la década", encarnando "la apoteosis del mal gusto." Sostiene además que "a diferencia del cine - que ya había librado a principios de siglo la batalla sobre su valor social y su capacidad para producir cultura-, la radio es un medio ausente en la revista" hasta que a fines de la década del 30, publica un artículo titulado: ¿Habrá que suprimir la radio? de Eduardo González Lanuza, donde el autor denosta no sólo el género, sino al medio en su totalidad (González, 2008:143). Por su parte, el diario católico El Pueblo1, en su sección "A través del éter", denunciaba desviaciones morales presentes en los radioteatros más populares.

Ahora bien, la concepción que los actores y actrices tienen de su propio métier constituirá el quid de la cuestión, y permitirá -o no- consolidar una identidad compartida que permita visibilizar necesidades y problemáticas comunes.

Como sostiene Dubatti sobre los años 30, "el mapa teatral porteño es extenso y complejo, porque la franja comercial, que manejan los capocómicos y los empresarios, en 
tensión con los dramaturgos y con muchos actores de menor figura, no es la única" (2013:21-2). El reconocimiento no sólo de los diferentes circuitos, sino incluso de categorías y clases al interior del colectivo actoral no puede ni debe ser soslayado. En el teatro comercial, como es sabido, los capocómicos gozaban de condiciones laborales privilegiadas frente al resto de la compañía. En el cine, sucederá algo similar, y en la radio, con el correr de los años, también.

Cabe preguntarnos entonces, ante estas divisiones de tan diversa índole, cuáles eran las reales posibilidades de consolidar un incipiente relato colectivo en tanto trabajadores y trabajadoras de la cultura durante la década del 30. Sergio Pujol, sobre esta cuestión, sostiene que "más aún que la música popular, el radioteatro será duramente cuestionado desde la 'alta cultura' teatral, casi en relación proporcional con su notable arraigo popular" (1994:231).

En esta alta cultura teatral podemos encontrar dos vertientes:

» Desde 1924 funcionaba el Conservatorio de Música y Declamación, donde se formaban los actores cultos en la dicción interpretativa, técnica de actuación que consistía fundamentalmente en decir correctamente el texto. Aquí debemos subrayar la hegemonía del texto y del autor por sobre el quehacer actoral propios de la época. Entre los profesionales más renombrados de entonces figuranestán Lola Membrives, Elsa O'Connor, Guillermo Battaglia, Narciso Ibáñez Menta, Rosa Rosen. Estos dos últimos llegarán al radioteatro sólo en 1942, cuando el género ya se encontraba institucionalizado y de algún modo reconocido.

"Además, la década del 30 ve nacer los grupos de teatro denominado independiente, con su mayor exponente en la figura de Leónidas Barletta y su Teatro del Pueblo. Conducta, su segundo órgano oficial luego de Metrópolis, en 1942 publica dos páginas sin firma donde el radioteatro es denominado "factor de embrutecimiento colectivo", y la radiofonía "enemigo público número uno de la cultura". En el mismo texto se reconoce nuevamente el carácter comercial del género y se establece de manera implícita una categorización en el colectivo de actores y actrices que ya existía en el teatro. Si bien sólo se menciona que para el "actor consciente, el artista" el radioteatro sería "un absurdo", entendemos, por oposición, que existe un otro, aquel que efectivamente trabaja y acepta las reglas del dispositivo, y que, en consecuencia, no merecería llamarse artista. Es claro y bien conocido el pensamiento de Barletta y su círculo de artistas-militantes. Las críticas hacia los actores y actrices del radioteatro abarcaban cuestiones estéticas e incluso éticas, y aquello que anteriormente se criticaba en el teatro popular volvía a señalarse en el nuevo género. Pellettieri señala al respecto, que "a partir de los 30, cuando los géneros populares se convierten de marginales en desplazados (...), el actor popular, el histrión, una forma simple de actor, se refugió nuevamente en el circo, y luego en la radio." (2001:12). Efectivamente, los radioteatros recogieron tradiciones teatrales populares y convocaron a sus artistas. Repusieron temáticas y números musicales ya consagrados años antes en los escenarios. Hubo cantantes folkóricos como Mario Amaya -que será Churrinche en Chispazos de Tradición-, músicos de tango como Juan Caldarella, locutores como Rafael Díaz Gallardo, el villano, y actores y actrices que ya contaban con experiencia en las tablas como Tita Galatro, Domingo Sapelli, Raquel Notar (Chispazos de Tradición, 1932), Miguel Gómez Bao, Lucía Barausse (Ronda Policial, 1933), o Juan Velich, Mecha Caus, Maruja Pais, Roberto Salinas (Bajo la Santa Federación, 1933). Si bien determinados artistas poseían un reconocimiento previo al acceso a la programación radiofónica, trabajar en la radio no implicaba necesariamente ser un astro o una estrella. Para acceder a dicha categoría era necesario llegar al cine. Marta Casale sostiene que en el primer film sonoro Tango! (Luis José Moglia Barth, 1933) es notorio el aporte de cierto capital simbólico de los protagonistas. "El renombre logrado en otros ámbitos artísticos, ciertos roles o tipos ya transitados y el afecto del público con el que ya 
contaban, (...) permite suponer la prexistencia de cierto sistema de estrellas en el teatro -también en la radio-, que el cine toma, usa, potencia y perfecciona." (Casale, 2018: 249). Ese capital simbólico adquirido en la radio estaba fundamentalmente ligado a la música, donde los y las cancionistas lograron el reconocimiento y favor de la audiencia. Tomemos el caso de Azucena Maizani, cancionista estrella que en 1933, al regresar de su gira por Europa, fue contratada por Radio Belgrano por \$4000 mensuales, o de Mercedes Simone, que en 1937 cobraba \$7200 mensuales, mientras que Eva Duarte, en su debut en el radioteatro y habiendo ya participado en teatro y en cine, en el mismo año, cobró \$180 por mes en la misma emisora.

A propósito de las cifras que se manejaban en la época, Marysa Navarro sostiene que en el teatro,

(...) los actores de la categoría de Evita ganaban de 60 a 100 pesos mensuales, trabajando dos funciones diarias y tres los domingos y días de fiesta. Teniendo en cuenta que un litro de aceite Ybarra costaba $\$ 8,50$, un traje de hombre $\$ 75,00$, y un vestidillo cualquiera de mujer unos $\$ 50,00$, apenas les alcanzaba para vivir y casi nunca para pagar las deudas que podían acumular en los meses sin trabajo. Si un actor conseguir vivir al día, podía considerarse afortunado (1994:39).

Debido a la miserabilidad de los sueldos, los actores y actrices, muchas veces, debían buscarse otros trabajos para poder sobrevivir. Muchas actrices, por ejemplo, solían hacer fotos o cine de publicidad y tanto mujeres como hombres encontraron en el radioteatro un empleo más rentable, pero convertirse en una estrella y lograr contratos como tales a partir de la participación en dicho género demandará aún algunos años.

\section{Representación gremial y conflictos identitarios}

Hemos presentado la disgregación de los actores y actrices en distintos medios, categorías, clases y circuitos como un gran obstáculo en la construcción de una identidad colectiva que permita la consolidación del YoActor, y como sostiene Mauro, los años 30 constituyen un

momento de crisis muy profunda dentro del gremio actoral, no sólo por los altísimos niveles de desocupación entre sus afiliados, sino por el surgimiento de ámbitos de trabajo que no contaban con representación sindical ni con normativa alguna, como la radio y el cine. Según Klein (1988), en 1933 sólo trabaja el $36 \%$ de los mil ochocientos afiliados a la Sociedad Argentina de Actores, lo que no incluye a los setecientos artistas que se desempeñaban en la radio y en el cine (2018b: 213).

De este modo, si hacemos el cálculo, en el año de explosión del cine y del radioteatro eran más los artistas que trabajaban en estas nuevas industrias que aquellos afiliados que lo hacían en el teatro. Nos encontramos, entonces, frente a un alto porcentaje de artistas que aun desempeñándose en la actuación no encontraban representación gremial (Velasco, 2012; Mauro, 2018a, 2018b). Con la transformación de la industria del entretenimiento y la crisis económica generalizada, la entidad que había nacido en 1919 ante la necesidad de los actores y actrices de reclamar por sus derechos laborales, fue perdiendo una gran cantidad de socios:

Desciende el grado de participación societaria a niveles mínimos: un presidente se elige en 1934 con sólo 15 votos. Las amnistías a los morosos no tienen resultado. 
A ello se agrega el surgimiento de dos importantes fuentes de trabajo: la industria cinematográfica y, en especial, el radioteatro, actividades no contempladas por la AAA en aquella época (Klein, 1988:21).

La Sociedad Argentina de Actores afrontaba importantes conflictos internos entre grupos mutualistas y grupos sindicalistas. Durante toda la década del 30 continuaran las disputas entre actores y actrices y los empresarios, pero siempre en el ámbito del teatro, sin contemplar la gran cantidad de profesionales que seguían incorporándose a los nuevos medios.

Es a partir de la década del 40, cuando la institucionalización del género adquiere cierto grado de legitimidad. Actores y actrices que son propios de los radioteatros comienzan a ocupar con su imagen páginas de revistas como Radiolandia y Sintonía. (Lindenboim, 2013). En ésta última, sostiene Casale (2018), se dará cuenta del cambio en el flujo de artistas, donde estrellas de la pantalla de cine desembarcarán en los radioteatros mejorando en ciertos aspectos las condiciones laborales sostenidas hasta el momento.

Por otra parte, Máscara, órgano oficial de la Asociación Argentina de Actores, comienza a editarse en septiembre de 1940, y desde el primer número ofrece una sección llamada "La radio al día", donde los directores artísticos de las principales emisoras radiales son entrevistados y responden específicamente sobre el radioteatro instando a actores y actrices profesionales a participar y así elevar el nivel cultural de las emisiones. Quizás la contribución voluntaria que recibía la revista de la AAA por parte de la Compañía Radioteatral Porteña haya sido un incentivo para el incipiente reconocimiento. (Máscara $\mathrm{N}^{\circ} 2,1940$ )

Pero la institución continuaba teniendo como miembros sólo a actores y actrices de teatro mientras que existía otra asociación que nucleaba a los artistas de circo y de variedades (payasos, magos, ilusionistas, coristas, ventrílocuos, encantadores de animales, etc.), la Unión Argentina de Artistas de Variedades (Shirkin, 2018) que según Velasco "creó una diferencia de identidad entre los actores y actrices de teatro, teóricamente más ilustrados, y "los otros" de "tercera categoría" (Velasco, 2012:284).

Finalmente, en 1943, se fundan dos entidades que tendrán posiciones ideológicas muy diferentes en un futuro próximo: por un lado, la Asociación Gente de Radioteatro, que luego se afiliará a la Federación Argentina del Espectáculo Público en 1945, y, por otro, la Asociación Radial Argentina (ARA), fundada por Eva Duarte, y que, según Lindenboim "no será parte de esa formación, sino todo lo contrario". Con respecto a esta última, el autor continúa diciendo que "se trató de un intento de encuadrar a los trabajadores dentro de una organización controlada por el Estado, pero que no tuvo ni muchos afiliados o miembros, ni iniciativas destacadas, ni tampoco una continuidad en el tiempo" (2019:14).

Volviendo a la Asociación Gente de Radioteatro, y según Berman, la misma se habría creado "para promover el mejoramiento económico, cultural y social de todos los trabajadores del radioteatro", ya que "entre sus fines explícitos se encuentra el de unir a toda la familia radioteatral, contribuir a su mejora y elevar el concepto de la ética profesional", y "no se presenta como una institución dispuesta a ordenar los destinos de un nuevo género, sino que aparece para torcer los caminos desviados del mismo."(Berman, 2018:306-7). A diez años de los primeros radioteatros, desde su estatuto, la institución definía quiénes quedaban incluidos y quienes no: los actores y actrices, los titulares de compañías, cabeza de compañía, directores, montajistas sonoros, relatores en sketches y los libretistas formarían parte del sindicato, no así 
los locutores comerciales ni los autores que tenían sus propios espacios de representación. Respecto a las principales preocupaciones, la Asociación reclamaba específicamente por el derecho de jubilación, por un régimen nacional de trabajo que fije un sueldo mínimo digno y por la estabilidad laboral de lxs artistas amenazada por los cambios de reparto. Los radioteatros no podían durar más de veinticinco días de transmisión por reglamentación estatal, lo que generaba una gran incertidumbre en lxs trabajadorxs. Además se señalaba que, en el momento de fundación, solo dos emisoras mantenían sus elencos estables, lo cual, sin duda, agravaba la situación y generalizaba la preocupación en el sector.

En síntesis, Lindeboim sostiene sobre estas primeras experiencias gremiales en el rubro radial que hacia 1943

La mayoría de estas organizaciones carecían de personería jurídica y no eran parte de la CGT, todavía manteniéndose autónomamente. Por eso, sin ser parte de una entidad supra sindical, y sin tener el reconocimiento estatal para funcionar como representantes institucionalizados de los trabajadores, era difícil mostrar poder a la hora de las negociaciones con la patronal, y solía predominar el perfil mutualista más que el sindical (2019:7).

Durante el decenio siguiente se reconfigurará el campo sindical y los diferentes gremios del espectáculo y de los medios de comunicación tendrán un rol de gran importancia en la historia argentina.

\section{El caso Eva Duarte}

Si bien la vida de Eva Duarte fue analizada y estudiada por numerosos autores, creemos que contribuye a los propósitos de este trabajo poner de relieve algunas cuestiones de su vida artística. ${ }^{2}$

Eva Duarte comenzó su carrera como actriz en 1935 en el Teatro Comedia, haciendo un pequeñísimo papel en La Señora de Pérez. Ya había intentado incursionar en el mundo del espectáculo participando de pruebas y concursos radiales para declamar y recitar poesías sin demasiado éxito. Es en el ámbito teatral donde da sus primero pasos en la actuación y formará parte de varias compañías teatrales con las cuales realizará giras por el interior de la Argentina.

El teatro no le permitía más que vivir con lo justo y no representaba una actividad redituable. Por otro lado, su presentación en el cine demuestra, como sostuvimos anteriormente, la dinámica de las nacientes industrias culturales. En 1937, Eva Duarte participa y gana un concurso organizado por la revista Sintonía. Éste ofrecía a las jóvenes aspirantes a la fama, la posibilidad de ser tapa de la revista y hacer una aparición en el film ¡Segundos afuera! de Chas de Cruz y Alberto Etchebehere. A la actividad teatral y cinematográfica, se sumará su incorporación a la compañía de radioteatro "Remembranzas", en Radio Belgrano. Más tarde, en agosto del mismo año, debuta como Esther en Oro Blanco, obra adaptada por Manuel Ferradás Campos. Será el primero de los radioteatros en los que Eva Duarte participe y se convertirán en su principal fuente de trabajo.

2 Véanse como ejemplo Borroni y Vacca (1970), Dos Santos (1983), Pichel (1993, 1996), Navarro (1994), Dujovne Ortiz (1995), Castiñeiras (2001, 2003), Pigna (2007), Vasallo (2009), Galasso (2012), y específicamente sobre su vida artística, Bra (1986) y Maranghello (2016). 
La radio, además, le permitirá ser reconocida popularmente. En 1939, Antena y Sintonía colocan la figura de Eva en la portada de la revista. En esta última, junto al actor Alberto Vila, se lee un epígrafe que dice: "dos celebradas figuras del elenco artístico de Radio Prieto" (Sintonía, 25 de octubre 1939). El 13 de diciembre de 1939, aparecerá en la tapa de otra revista, Damas y Damitas. Vera Pichel, secretaria de redacción, refiere:

En aquellos años la gente de teatro no tenía promotores publicitarios ni agentes de prensa. Cada cual debía arreglarse como podía para la publicación de una foto o de una notita. (...) Las jóvenes actrices visitaban en nuestro medio, las redacciones, casi sin anuncio previo. Llegaban con sus fotos o notitas en la mano y solicitaban la publicación correspondiente, agradeciendo, como quien dice, con sonrisa previa. A veces se publicaban, a veces no. Con Evita el manejo fue distinto. Se anunció por teléfono pidiendo una entrevista con la secretaria de redacción. Desde ya que accedí, y llegó a la mañana siguiente. (...) -Soy actriz de radioteatro-dijo-, me llamo Eva Duarte y necesito una foto en la tapa de su revista para llegar a ser cabeza de compañía. Las tapas de revista no eran competencia de la secretaria de redacción, por lo cual le ofrecí hablarlo con el director. Eva insistió: -No. No tengo mucho tiempo y no confío en los directores. Por eso vengo a verla a usted. (...) Y ¿sabe por qué vine a verla? ... Porque una mujer que trabaja entiende a otra mujer que trabaja -seguía diciendo- y usted tiene que entenderme (Castiñeiras 2003: 93).

Hay varias cuestiones centrales en este testimonio: Eva Duarte no sólo se autopercibe como actriz de radioteatro y mujer trabajadora, sino que además podemos percibir un alto grado de consciencia sobre el funcionamiento de las industrias culturales de la época. Ya en 1938 se había afiliado a la Asociación Argentina de Actores y resulta evidente que sus inquietudes y sus necesidades no hallaban respuesta en dicha asociación. El 3 de agosto de 1943, Eva participó de la fundación de la Asociación Radial Argentina, una entidad gremial que pretendería defender los derechos de los trabajadores de la radiofonía. En esa época, debemos recordar que Eva Duarte ya era considerada una primera actriz del radioteatro, de renombre y reconocimiento.

El 17 de mayo de 1944, la Asociación Radial Argentina (ARA) fue reconocida por la Secretaría de Trabajo como la única entidad que podía representar artistas de la radio y a Eva Duarte en la función de presidirla. Lindenboim analiza el desempeño de esta asociación y sostiene que "en el conjunto de bibliografías sobre Evita, en los trabajos sobre el período, casi no hay información sobre ARA, ni volantes, ni espacios de reuniones, actas, integrantes de comisiones directivas, afiliados, etc. Es muy poco lo que se conoce sobre la vida de este sindicato" (2019:14-15).

Más allá de la escasa o nula actividad del ARA, lo que pretendemos subrayar en este apartado es la posibilidad concreta de la asunción de una identidad política. La posibilidad de reconocerse en tanto mujer-actriz-trabajadora en la naciente industria de la radiofonía y plantear la necesidad de defender los derechos laborales constituye una perspectiva interesante para analizar las políticas culturales que tendrán lugar en los sucesivos gobiernos argentinos. Eva tenía veinticuatro años en el momento de fundar ARA.

\section{Revista Máscara: debates éticos, estéticos y mercado laboral}

En septiembre de 1940, la Asociación Argentina de Actores comienza a editar la revista Máscara. En la sección "La radio al día" se publicaron a lo largo de los diez primeros números, entrevistas a los directores artísticos de las radios más importantes del país, las declaraciones son elocuentes respecto a las cualidades estéticas y condiciones de 
producción de los radioteatros hasta el momento. Podemos sostener que empiezan a configurarse de este modo, otro tipo de relaciones entre sectores de campo artístico.

En el primer número de la revista, Pablo Valle, director de radio El Mundo, una de las emisoras líderes, destaca la importancia que el radioteatro tiene para su empresa y el trato que se les ofrece a los actores de su elenco estable comparándolo con otras radios. Sostiene que en El Mundo nunca se dio lugar a emisiones que "exaltan bajas pasiones y por ende molestan y degradan la cultura popular" (Máscara, $\mathrm{N}^{\circ} 1: 20$ ). No deja pasar la ocasión para mencionar la completa adecuación de sus productos radioteatrales a las disposiciones emanadas por la Dirección de Correos y Telégrafos, aquellas que reglaban la autorización de las emisiones buscando elevar el nivel moral e intelectual de los oyentes.

En abril de 1941, Di Lielo, director de Radio Belgrano, otra de las emisoras más exitosas, reconoce que hay un "problema complejo" ya que no "se ha llegado al grado de perfección que anhelamos...", y continua diciendo que los autores deben comprender su responsabilidad y "que sus obras no deben alentar odios ni rencores, sino exaltar siempre el amor y la verdad (...) Así contribuirán a la elevación cultural del pueblo" (Máscara, $\mathrm{N}^{\circ} 8:$ 20). Nuevamente se subraya la finalidad didáctica que idealmente debían tener todas las producciones radiales. También se expresa sobre la formación de elencos y las condiciones para poder desempeñarse en el radioteatro

¿Basta solamente "saber leer" para ser buen actor radioteatral? Creo que no. Hay que saber interpretar por eso juzgo interesante la labor de los actores teatrales que nos trae el aporte de su experiencia adquirida... Claro que antes deben adaptarse al micrófono, pero esto no es una dificultad insalvable y menos ahora que Radio Belgrano ha implantado el radioteatro con apuntador, lo que permite trabajar sin la preocupación de la lectura. Asociemos nuestro esfuerzo para dignificar el radioteatro (Máscara Nº: 20).

Di Lielo, como Valle, resalta dos cuestiones importantes: la necesidad del aporte de los actores teatrales y las condiciones favorables en las que trabajan los actores y actrices en sus emisoras.

Ahora bien, serán más contundentes, en varios aspectos, los dichos de los directores artísticos de otras emisoras con menor nivel de audiencia y que resultan más explícitas en cuanto al cambio que operó en la Asociación Argentina de Actores respecto del medio.

Isidro Odena, director artístico de Radio Stentor desde 1931, reconoce en el radioteatro un "arte sutil y complejo bastardeado entre nosotros por autores mediocres y actores improvisados" (Máscara $\mathrm{N}^{\circ} 2,1940: 20$ ), criticando fuertemente el desempeño de quienes hacen radioteatro. Pero fundamentalmente da cuenta de una toma de consciencia respecto a la situación del mercado laboral:

Ahora que el teatro se debate en una crisis muy grave, que origina la desocupación y el pauperismo de los comediógrafos y cómicos, convendría reflexionar sobre las posibilidades que ofrece el radioteatro a los profesionales de la escena. Y sería oportuno predicar una mayor preocupación y un mayor respeto en torno a la labor microfónica (...) Dejo esta reflexión para que se la comente en el café, obligado refugio de los exiliados del teatro en esta triste hora de crisis y con el sincero propósito de beneficiar a la gente de teatro sin ocupación y de paso al radioteatro argentino, tan huérfano de valores estimables" (Máscara ํ2, 1940:20). 
Y agrega que con la participación de los profesionales en el radioteatro se lograría conformar una "consciencia artística del radioteatro" o sea, inexistente hasta el momento.

Tanto Julio Gallino de Radio Excelsior como Enrique Gil, director de Radio Argentina coinciden en "la necesidad de incorporar al radioteatro el mayor número posible de actores profesionales, con experiencia, desde luego seleccionando entre ellos a los que realmente posean las aptitudes esenciales al interprete radiotelefónico" (Máscara $\mathrm{N}^{\circ} 4,1940: 20$ ).

Entrado el año 1941, en el número 7 de la revista, Alfredo Gregorio, el director de Radio Cultura, expresa de una manera contundente el pensamiento del campo intelectual argentino

no se puede presentar ante el micrófono una obra seria, ni comedia en la que se destaque un fino humorismo porque ya sabemos que el público oyente prefiere todo lo otro: la eterna llorona o el sempiterno payaso (...) Estamos en un círculo vicioso del que no salimos porque no podemos contrariar los gustos del público, $Y$ esto no es sino un error que ha cristalizado a nuestro radioteatro en sus peores manifestaciones y que, por eso mismo no puede ser considerado como elemento cultural (...) Actores y autores de prestigio se hallan alejados del micrófono. Porque, naturalmente, la actuación de los unos, sobria, seria, no despertaría la atención del público (Máscara $\mathrm{N}^{\circ} 7,1941: 20$ ).

Por último, Teodoro Prieto, de Radio Prieto, en una posición más moderada, pero que sigue los mismos lineamientos, describe la doble finalidad que un producto como el radioteatro debería tener: satisfacer la vida emocional vehiculizando el conocimiento de las grandes obras universales a través de adaptaciones. Incluso reconoce que hay cierto progreso, pero debido a la presencia de "autores de solvencia" y de "figuras de muy alta cotización en los escenarios teatrales" (Máscara $\mathrm{N}^{\circ} 10,1941: 20$ ). Se reitera la cuestión de la doble finalidad del medio, y se subraya la importancia del carácter reproductor y no de productor de bienes culturales.

Con el análisis de los testimonios, podemos afirmar que esta sección fue pensada y desarrollada en una relación de alianza entre agentes del campo artístico, que luego de una década de debates pudo consolidarse. La Asociación Argentina de Actores reconocía y promovía una actividad entre sus asociados que había sido menospreciada y denostada, y que frente a la profunda crisis que atravesaba el teatro, se convertía ahora en una buena opción, una salida laboral digna.

Los directores artísticos de las radios, por su parte, declaraban su preocupación sobre la baja calidad de algunos productos, problema que podría ser resuelto con la incorporación de profesionales de la actuación. Además, las radios más importantes subrayaban las condiciones laborales ofrecidas, en una clara puja interna por captar figuras centrales del campo artístico.

\section{Conclusiones}

Hemos intentado en este trabajo dar cuenta de la compleja dinámica del campo intelectual y del campo teatral en el momento de explosión de las industrias culturales del siglo pasado. Específicamente con la aparición y consolidación del radioteatro, las reacciones de la prensa especializada, de los intelectuales, y de los propios actores y actrices en su organización gremial fueron de rechazo frente a una actividad que no 
sólo otorgaba gran reconocimiento popular sino que generaba puestos de trabajo en un contexto de crisis. El desprestigio de los radioteatros en tanto productos meramente comerciales iba de la mano de concepciones sobre el arte y la cultura que ya habían condenado anteriormente al teatro popular.

Si bien podemos considerar que hubo un intercambio fructífero entre actores de teatro que se incorporaron a la radio, gran fuente de trabajo, y los actores de radio que se sumaron al teatro, desde la perspectiva de los agentes centrales del campo teatral del momento, ¿cuál fue la percepción sobre este fenómeno? Nicolás Fregues, el presidente de la AAA, a pesar de ofrecer espacio en la revista Máscara para visibilizar el radioteatro como un importante espacio laboral para lxs asociadxs, en 1941 aún veía al cine y a la radio como grandes adversarios para la actividad teatral, sin comprender las posibilidades de desarrollo que estos medios ofrecían para lxs profesionales de la actuación y que sí pudieron captar otros agentes que ocupaban posiciones periféricas en el campo (Máscara $\mathrm{N}^{\circ} 10,1941$ ).

Fueron muchos los actores y las actrices que necesitaban trabajar y que no dudaron en recalar en el radioteatro y desarrollar allí su carrera artística a pesar de las críticas y de la falta de reconocimiento de sus pares. Ricardo Oriolo, actor formado en el circo criollo que luego paso a formar parte del elenco de Atilano Ortega Sanz, de Radio Mitre, decía al respecto:

El radioteatro, igual que el circo, cumplió una gran misión. Fue llevar el teatro donde nadie se arrimó jamás para hacer una función. Una verdadera misión que no la cumplieron grandes actores, grandes figuras de la calle Corrientes, porque no iban a los pueblos chicos. Iban solo a las ciudades importantes (...) el circo y el radioteatro fueron verdaderas escuelas de teatro (Seibel, 2005:226).

Oriolo no sólo destaca la función social del radioteatro, sino que demuestra plena consciencia de la división entre grandes actores, figuras y artistas de circo o elencos populares.

Lucha Sosa, otra artista formada en el circo, cuenta que en el año 1938 le ofrecieron incorporarse a Radio Belgrano para trabajar en un famoso radioteatro y dice: "En esa época entrar a Estampas porteñas era tocar el cielo con las manos. Como hoy en día que te llamen para encabezar una tira en el canal de televisión de mayor rating o algo así" (Seibel, 2005:174). La comparación con la televisión no hace más que subrayar la popularidad de la que gozaban los artistas del radioteatro y, al mismo tiempo, reformula la discusión sobre la legitimidad de los medios masivos de comunicación como productores de bienes culturales y lugares estratégicos en las trayectorias artísticas de actores y actrices.

Ribeiro Veras señala que "la popularización de tecnologías impactó y, de cierta manera, unificó el mercado de diversiones en la región [América Latina] y transformó definitivamente al artista en trabajador" (2015:275). El problema, entonces, creemos que fue la autopercepción en cuanto tales de los sectores cultos del teatro, que marginaron a aquellxs que trabajaban en las nuevas industrias culturales.

Ante los interrogantes que fueron planteados a lo largo del trabajo sobre el desarrollo de una identidad actoral, podemos concluir, siempre de manera provisoria, que la aparición de un nuevo género en un nuevo medio, que abrió nuevas posibilidades laborales en un contexto de crisis generalizada, no fue percibido en los primeros años por el colectivo de actores y actrices profesionales como un espacio desde donde afianzarse en la lucha por sus derechos laborales y por el reconocimiento de la actividad. 
Con el transcurrir de la década se reajustarán algunas posiciones en el campo teatral y habrá desplazamientos, aunque más no sea aquel semántico, que demostrará algunos cambios en el modo de pensar la relación Artista-Mundo del Trabajo desde la propia Asociación Argentina de Actores.

Recordemos que en el Boletín oficial del 1 de Mayo de 1920 de la Sociedad Argentina de Actores, declaraba a propósito del Día del Trabajador: “... nosotros, la gente de teatro, (...) no queremos que se nos llame trabajadores ni podemos permitir que como tales nos considere (...) Somos actores, nosotros, no obreros..." (Boletín AAA 1/5/1920). Para agosto de 1943, Ribeiro Veras señala que

\begin{abstract}
muchos periódicos porteños divulgaban la nota emitida por la AAA en medio del conflicto entre autores y empresarios teatrales por el tema del pago de porcentaje por platea y de los carteles libres. La AAA se ponía junto a la asociación de autores diciendo [en el diario Crítica del 13 de agosto de 1943]: Las relaciones del actor con el empresario no son, ni pueden ser otras que las del obrero o empleado frente al patrón o empleador (2015:281).
\end{abstract}

Durante el período analizado comenzó entonces a desarrollarse una incipiente toma de consciencia en cuanto a la forma de percibirse. El radioteatro fue un fenómeno cultural que avivó los debates sobre la producción y reproducción de bienes culturales y en consecuencia, sobre los productores y agentes involucrados en dichas actividades. A pesar de estos pequeños pasos en el camino hacia la configuración del Yo-Actor, al interior del colectivo de actores y actrices continuaron y continúan aun hoy existiendo divisiones y categorías que atentan contra la posibilidad de jerarquización de su trabajo.

Creemos, para concluir, que en la actualidad, la aparición de otros medios, de otros circuitos y de los diferentes lugares de formación, constituye un desafío para el colectivo actoral. La importancia de conocer y reconocerse en algunas experiencias del pasado que este trabajo intentó presentar, permitirá seguir construyendo un relato identitario común, donde la heterogeneidad pueda ser reconocida como un valor y no como un obstáculo, posicionando el trabajo actoral en su verdadera dimensión productiva. 


\section{Dibliografía}

" Berman, M. y Fraticelli, D. (2008). “Del estado del radioteatro antes del teleteatro”. Revista L.I.S. Letra. Imagen. Sonido. Ciudad Mediatizada N 1 , Facultad de Ciencias Sociales UBA; pp. 71- 82, [en línea] Consultado el 14 de febrero de 2019 en https://publicaciones.sociales.uba.ar/index.php/lis/article/view/3619

"Berman, M. (2010). "Las huellas de la ciudad en los primeros radioteatros" Revista L.I.S. Letra. Imagen. Sonido. Ciudad Mediatizada N 5 , Facultad de Ciencias Sociales UBA, pp. 134-143, [en línea] Consultado el 8 de febrero de 2019 en https://publicaciones.sociales.uba.ar/index.php/lis/article/view/3685

» Berman, M. (2018). La construcción de un género radiofónico: el radioteatro. Buenos Aires: Eudeba.

» Bourdieu, P. (2000). Intelectuales, política y poder (Trad. A. Gutiérrez). Buenos Aires: Eudeba.

» Bourdieu, P. (1967). “Campo intelectual y proyecto creador”. En AAVV Problemas del estructuralismo. México: Siglo XXI.

"Casale, M. (2018). “El actor en el star system argentino ¿trabajador privilegiado o mero producto?”. telóndefondo.org. Revista de Teoría y Crítica Teatral, Año 14, Nro. 27, Buenos Aires: UBA, Facultad de Filosofía y Letras; pp.245-259, [en línea] Consultado el 10 de febrero de 2019 en http://revistascientificas.filo.uba. ar/index.php/telondefondo/article/view/5102

"Castiñeiras, N. (2003). El ajedrez de la gloria. Buenos Aires: Editorial Catálogos.

»Dubatti, J. (2013). "Después de Florencio Sánchez, la «declinación". Sobre el mito de la "época de oro" en la historiografía del teatro argentino." Revista Episkenion Revista de Teatro Contemporáneo $\mathrm{N}^{\circ} 1$, [en línea] Consultado el 12 de mayo de 2019 en https://www.episkenion.com/revista-de-teatrocontempor\% 3 \%A1neo/episkenion-n\%C3\%BAmero-1/

»Eliades, A. (2003). "Historia legal de la radio y la televisión en Argentina”. Revista Oficios Terrestre $\mathrm{N}^{\circ}{ }_{13}$, Facultad de Periodismo y Comunicación Social, UNLP, pp. 32-56, [en línea] Consultado el 15 de noviembre de 2018 en http://sedici. unlp.edu.ar/handle/10915/48546

" González, B. (2008). “El sonido de la Nación: la radio y el disco en Sur y Nosotros”. Revista L.I.S. Letra. Imagen. Sonido. Ciudad Mediatizada $\mathrm{N}^{\circ}$ 1. Facultad de Ciencias Sociales, UBA;141-149, [en línea] Consultado el 13 de febrero de 2019 en https://publicaciones.sociales.uba.ar/index.php/lis/article/view/3625

"González Leandri, R. (2001). "La nueva identidad de los sectores populares". En Cataruzza, A. (Dir.), Nueva Historia Argentina. Vol. 7. Buenos Aires, Sudamericana; 201-238, [en línea] Consultado el 2 de marzo de 2019 en http://www. terras.edu.ar/biblioteca/13/13HSARG_De_Privitellio_Unidad_3.pdf

" González Velasco, C. (2014). "Pasen y vean... Y escuchen y lean: El mercado de los espectáculos durante las entreguerras”. II Jornadas Política y Cultura en la entreguerras, Universidad Nacional de General Sarmiento, [en línea] Consultado el 30 de enero de 2019 en http://www.historiapolitica.com/datos/biblioteca/ decadatreinta_gonzalez\%2ovelasco.pdf

" González Velasco, C. (2012). Gente de teatro. Ocio y espectáculo en la Buenos Aires de los años veinte. Buenos Aires: Siglo XXI. 
»Karush, M. (2013). Cultura de clase. Radio y cine en la creación de una Argentina dividida (1920-1946). Buenos Aires: Ed. Ariel.

»Klein. T. (1988). Una historia de luchas. La Asociación Argentina de Actores. Buenos Aires: AAA. Recuperado en http://www.cositmecos.com.ar/images/pdfs/ gremios/actores_historia_de_\%2oluchas.pdf

"Lindenboim, F. (2019). "La Subsecretaria de Informaciones en los radioteatros: la construcción de hegemonía y una estética del peronismo en acto". I Jornadas Interdisciplinarias del IAE (Internacionales). [en línea] Consultado el 7 de febrero de 2019 en https://www.academia.edu/40408714/La_Subsecretaria_de_Informaciones_en_los_radioteatros_la_construcci\%C_ $3 \%$ B3n_de_ hegemon\%C3\%ADa_y_una_est\%C3\%Agtica_del_peronismo_en_acto

"Lindenboim, F. (2013). “El peronismo en las revistas de espectáculos”. VII Jornadas de Jóvenes Investigadores. Instituto de Investigaciones Gino Germani, Facultad de Ciencias Sociales, UBA, Buenos Aires [en línea] Consultado el 2 de febrero de 2019 en https://www.aacademica.org/ooo-076/129.pdf

»Lopez Barros, C. (2013). “De cómo un medio puede ver a otro: la audiovisualidad de la radio en los comienzos del cine sonoro argentino". Revista L.I.S. Letra. Imagen. Sonido. Ciudad Mediatizada $\mathrm{N}^{\circ}$ 4. Facultad de Ciencias Sociales: UBA, pp. 108 - 119, [en línea] Consultado el 2 de abril de 2019 en https://publicaciones.sociales.uba.ar/index.php/lis/article/view/3751

»Mauro, K. (2018a). "Entre el mundo del arte y el mundo del trabajo. Herramientas conceptuales para comprender la dimensión laboral del trabajo artístico". telondefondo.org. Revista de Teoría y Crítica Teatral, Año 14, Nro. 27, Buenos Aires: UBA, Facultad de Filosofía y Letras; pp. 114-143, [en línea] Consultado el 2 de febrero de 2019 en http://revistascientificas.filo.uba.ar/index.php/telondefondo/article/view/5097

» Mauro, K. (2018b). “Identidades y apelaciones antagónicas de los trabajadores del espectáculo (1902-1955)". telondefondo.org. Revista de Teoría y Crítica Teatral, Año 14, Nro. 27, Buenos Aires: UBA, Facultad de Filosofía y Letras; pp. 176-231, [en línea] Consultado el 2 de febrero de 2019 en http://revistascientificas.filo. uba.ar/index.php/telondefondo/article/view/5100

» Mauro, K. (2014a). “El <<Yo Actor >>: Identidad, relato y estereotipos”. Revista Aura, Revista de Historia y Teoría del Arte, Año 1, Nro. 2, Tandil: Facultad de Arte de la Universidad Nacional del Centro de la Provincia de Buenos Aires [en línea] Consultado el 2 julio de 2017 en http://www.ojs.arte.unicen.edu.ar/index. php/aura/article/view/103

» Mauro, K. (2014b). "Elementos para un análisis teórico de la actuación. Los conceptos de Yo Actor, Técnica de Actuación y Metodología Específica". telondefondo.org. Revista de Teoría y Crítica Teatral, Año 10, Nro. 19, Buenos Aires: UBA, Facultad de Filosofía y Letras, [en línea] Consultado el 4 de agosto de 2017 en http://revistascientificas.filo.uba.ar/index.php/telondefondo/article/ view/6628

"Matallana, A. (2013). "Inventando la radio comercial: apuntes para una biografía de Jaime Yankelevich”. Revista de Instituciones, Ideas y Mercados № 58, pp. 147-166, [en línea] Consultado el 10 de enero de 2018 en http://www.eseade. edu.ar/wp-content/uploads/2016/o8/riim58_matallana.pdf

"Navarro, M. (1994). Evita. Buenos Aires: Editorial Planeta.

»Pellettieri, O. (2002) “Introducción”. En Historia del Teatro Argentino en Buenos Aires, Vol. II. Buenos Aires: Galerna. 
»Pellettieri, O. (2001). De Totó a Sandrini: del cómico italiano al "actor nacional" argentino. Buenos Aires: Galerna. Instituto Italiano de Cultura de Buenos Aires.

"Pujol, S. (1994). Valentino en Buenos Aires. Los años veinte y el espectáculo. Buenos Aires: Emecé.

》 Ribeiro Veras, F. (2015). “De los palcos a los gremios. La organización laboral de los actores en Río de Janeiro y Buenos Aires entre 1930 y1945". C \& $P, N^{\circ}$ 6. Bucaramanga, pp. 272-306, [en línea] Consultado el 20 de enero de 2018 en https://revistas.uis.edu.co/index.php/revistacyp/article/view/7100

"Seibel, B. (2005. Historia del circo. Buenos Aires: Ediciones del Sol.

»Shirkin, S. (2018). “El artista de variedades en el Buenos Aires de principios de siglo XX". telondefondo.org. Revista de Teoría y Crítica Teatral, Año 14, Nro. 27, Buenos Aires: UBA, Facultad de Filosofía y Letras, [en línea] Consultado el 2 de febrero de 2019 en http://revistascientificas.filo.uba.ar/index.php/telondefondo/article/view/5099

\section{Revistas}

" Máscara $\mathrm{N}^{\circ}$ 1, septiembre 1940. Buenos Aires: Asociación Argentina de Actores.

» Máscara N², octubre 1940. Buenos Aires: Asociación Argentina de Actores

"Máscara N 4 , diciembre 1940. Buenos Aires: Asociación Argentina de Actores.

»Máscara $\mathrm{N}^{\circ} 7$, marzo 1941. Buenos Aires: Asociación Argentina de Actores.

"Máscara N8, abril 1941. Buenos Aires: Asociación Argentina de Actores.

» Máscara №10, julio 1941. Buenos Aires: Asociación Argentina de Actores.

»Sintonía, 25 de octubre de 1939, Año VII, Nro. 340. Buenos Aires: Ed. Haynes 